Article

\title{
Spouted-Bed Gasification of Flame Retardant Textiles as a Potential Non-Conventional Biomass
}

\author{
Sohail Yasin $1,2, * \mathbb{C}$, Massimo Curti ${ }^{2}$, Giorgio Rovero ${ }^{2}$, Munir Hussain ${ }^{3}$ and Danmei Sun ${ }^{1}$ \\ 1 School of Textiles and Design, Heriot-Watt University, Galashiels TD1 3HF, Scotland, UK; d.sun@hw.ac.uk \\ 2 Politecnico di Torino, Corso Giuseppe Pella, 13900 Biella, Italy; massimo.curti@polito.it (M.C.); \\ giorgio.rovero@polito.it (G.R.) \\ 3 Department of Polymer Science and Engineering, Zhejiang University, Hangzhou 310027, China; \\ munir.hussain44@yahoo.com \\ * Correspondence: soh.yasin@gmail.com or sohail.yasin@polito.it
}

Received: 9 December 2019; Accepted: 22 January 2020; Published: 1 February 2020

\begin{abstract}
Renewable energy from thermal valorization plays a key part in today's energy from natural cellulosic textiles that are resourceful biomass and safe from toxicity at high temperature treatments. The situation is opposite, when technical textiles are treated with synthetic chemical finishes adding functionality as anti-bacterial, water repellent or flame retardant, etc. Incineration of flame retardant textile results in possible unfavorable gases, toxic fumes and contaminated ash. Other thermal valorization techniques like gasification would assist in avoiding the formation of additional toxic hazards. Herein, gasification of flame retardant textile is carried out the likelihood to get quality gas composition. For comparative analysis, flame retardant textiles, after their flame retardant ability being revoked, are also gasified. The output gas components suggested that gasification can be a useful thermal valorization approach for flame retardant textiles and relevantly improved gas composition was seen in textiles with their flame retardant substrate/species being removed.
\end{abstract}

Keywords: thermal valorization; gasification; end-of-life; flame retardant; cotton

\section{Introduction}

Renewable energy from thermal valorization plays a key part in today's energy outlook and there is not a biomass replaceable to cotton. Thousands of tons of biomass residues produced from cotton industry with a thermal energy potential from combustion were estimated around $4000 \mathrm{TJ}$ annually [1]. With immense attention to cotton crops waste utilization, cotton products with synthetic functionalities like technical textiles are ignored in perspective of the thermal valorization panorama. In 2017, $€ 181$ billion turnover and $€ 4.9$ billion of investment were seen in the European textile and clothing industry and exports of technical textiles outside EU had increased $39 \%$, while imports reached to $32.6 \%$ more $[2,3]$. Flame retardant textiles are among technical textiles, used to withstand indoor safety regulations, consumption of which is also increased recently in the textile industry [4-6].

Flame retardants incorporated to textiles can be organic or inorganic in nature $[7,8]$, eventually make their way to landfills and incinerators. In the waste hierarchy, landfill being least preferable [9] and due to leachate of flame retardant chemicals [10], incineration is used commonly. Incineration constitutes a vast repository for toxic chemicals along with manmade or natural fibers, posing environmental emissions [11,12]. Even in developed countries, combustion of domestic waste in barrels, open pile, household heating stoves, primitive incinerators or fireplaces is carried on, significantly [13]. A part from the environmental concerns raised related to flame retardants from last three decades, originated from the potential release of toxin polybrominated dioxins, during the incineration of polybrominated diphenyls and diphenyl ethers [14,15], sustainable waste treatment of flame retardants is yet a challenge. 
Concerns over emissions of dioxin and similar persistent organic contaminants from the incineration of municipal solid waste (MSW) have been shown in various studies $[16,17]$. On the other hand, MSW combustion from other thermal valorization technologies, especially flame retardants is rather limited to date [12,18]. Thermal valorization technology like gasification is considered a more favorable method compared to incineration, as it converts material (biomass/organic mostly) to multipurpose fuel gas, known as the syngas $[10,19]$. The produced syngas is taken as synthesis reactant or a mere fuel for industrial use $[19,20]$.

Considering thermal valorization techniques for flame retardant cotton textiles, lower energy yield in incineration is obvious, due to incomplete combustion from chemical substrate applied on textile [6,21]. Moreover, from the combustion of flame retardant materials, the main thrust in incineration is given to the generation of carbon dioxide and monoxides, and other components. In previous study, an increase in heat release rate was realized by the degradation of flame retardant chemical on textiles using advanced oxidation process $[6,22]$. As in gasification, the quality of syngas is highly dependent on the content and properties of the material gasified, design and operative conditions and the gasifier itself [19]. Optimal gasification conditions and design have been studied previously for flame retardant textiles [10], it will be however interesting to see the content and properties of the syngas produced from such textiles.

For flame retardant textile waste treatment, incineration is practiced as the state of art technology. It is rare to find in literature on gasification acted as alternate disposal treatment of flame retardant textiles. Spouted bed reactors have demonstrated advantages in terms of medium gas consumption, pressure drop and the possibility to operate with coarse particles, compare to an equivalent bubbling bed unit [10,19]. They have been used in bench scale units for the pyrolysis of different solid wastes [23], besides their gasification process applications originally started from coal feed, to variant biomass and waste plastics as well $[24,25]$. They have been found successful with coarse particles and also with mixtures of coarse and fine particles [26]. They also expand the uniformity of feed particles, as irregular can plug or starve the feed and leads to lower gas yields [27]. Characterized by their flexible design, spouted bed reactors are capable to handle an irregular texture and particle size of the material fed which avoids the elutriation of the bed material compared to fluidized beds. Also, with short gas residence time, which limit tar conversion [28].

In this study, the quality and contents of syngas produced from the gasification of flame retardant cotton textiles is evaluated. Flame retardant textiles have undergone an advanced oxidation process (AOP) in order to degrade and removal of functional chemical substrate. A spouted bed unit is a particular type of fluidized reactor in which the gas for the fluidification is introduced from a single orifice placed at the bottom of the unit and, when the minimum spouting velocity is reached, it forms a fountain with high mixing properties. This kind of fluidification conveniently, specifically for coarse, sticky or agglomerating solids [29]. Generally, the performance of gasification depends on the operational conditions and reactor design [30]. Therefore, a pilot scaled spouted bed gasifier as a suitable technique is used for a potential thermochemical conversion of flame retardant cotton in present work. In the authors' knowledge, syngas analytics from the gasification of flame-retardant cotton textile and after its flame retardant substrate removed with an advanced oxidation process are not being carried out. This study portraits the promising applications of thermal valorization technology and experimental data analysis on gasification of non-conventional textile materials.

\section{Thermal Valorization Methodologies}

Incineration or combustion, pyrolysis and gasification are generic thermal valorization technologies, with their benefits and certain limitations. Incineration renders the material into ashes, whereas in pyrolysis and gasification set of reactions occur to carbonaceous materials as a thermal process to produce various by-products namely char and/or syngas. One method may favor to the other, in terms of operative conditions like temperature, pressure and amount of oxygen, nevertheless in reactor common reactions take place for all the methodologies [19]. Oxygen extensive 
and high-temperature exothermic reaction, combustion oxidize carbonaceous materials which yield water and carbon dioxide, are most commonly used for heat and steam production only. Whereas, gasification is an endothermic reaction, which generates hydrogen, methane and additional $\mathrm{CO}$ mixture at high temperatures, produced by an external exothermic reaction. Temperatures lower than gasification, pyrolysis takes place without oxygen and generates beneficial tars and a solid carbonaceous phase (char) [10,19].

Considering the toxin and ash filtration, incineration of flame retardant textiles is rather complicated and less beneficial as of incomplete combustion with lower energetic yield [6,31]. In addition, incineration of flame retardants not only produces higher carbon dioxide contents, but also major environmental hotspot for toxins near the reactors.

\section{Materials and Methods}

\subsection{Textile Palletization for Gasification}

Two cotton pellet samples for gasification were prepared [10]. The first cotton fabric with $170 \mathrm{~g} / \mathrm{m}^{2}$ is treated with durable organophosphorus flame retardant, namely Pyrovatex CP new by Huntsman, Wooldlands, the USA, having n-methylol dimethyl phosphonopropionamide (MDPA) as an active flame retardant component. The second sample comprise of cotton fabric with same properties as the first sample, but flame retardant substrate being degraded/removed from the surface of the fabric with an advanced oxidation process $[6,10]$.

The degradation of flame retardant substrate from cotton fabric was carried out using Fenton's reaction using concentrations; ferrous source $\left(\mathrm{FeSO}_{4} .7 \mathrm{H}_{2} \mathrm{O}\right) 500 \mathrm{~mL} / \mathrm{L}$ and $2 \mathrm{~g} / \mathrm{L}$ of hydrogen peroxide catalyst $\left(\mathrm{H}_{2} \mathrm{O}_{2}, 98 \%\right)$ per liter water at $\mathrm{pH}$. The reaction being highly oxidative, the fabric was kept for an hour, later fabric was neutralized by dipping it in a solution of $40 \mathrm{~g} / \mathrm{L}$ sodium hydroxide $(\mathrm{NaOH})$. Pellets of both samples were cut into $1 \mathrm{~cm}$ long, to be fed into the gasifier with a feeding rate of $150 \mathrm{~g} / \mathrm{min}$. The prepared pellet undergoes to the chemical reaction, while the inert sand (silica sand $1.4-1.8 \mathrm{~mm}$ ) is used to improve the fluidification and for thermal reasons.

In order to achieve continuous feeding and reach gasification temperature $\left(>700^{\circ} \mathrm{C}\right)$, there is a need to analyze syngas components. For this research, the experiments were performed with a pilot plant designed and built in Biella (Italy) which is capable of having material feeding of $200 \mathrm{~g} / \mathrm{min}$ to with thermal energy provide about $20 \mathrm{kWth}$ [32], 3D illustration of the experimental setup can be seen in Figure 1. The square-based unit which is the main component of the plant, has a side dimension of $0.2 \mathrm{~m}$ and $1.3 \mathrm{~m}$ in total, with its base inclined at $60^{\circ}$ angle. The chosen square-based unit is cost effective with lower heat dissipation compared with traditional circular one (multiple square based spouted bed for pyrolysis and gasification is under development). The prepared pellets are continuously fed in a conical shape hopper of the reactor. From hopper, the pellets go through a rotary valve with a specific feeding rate to the gasifier [32]. 


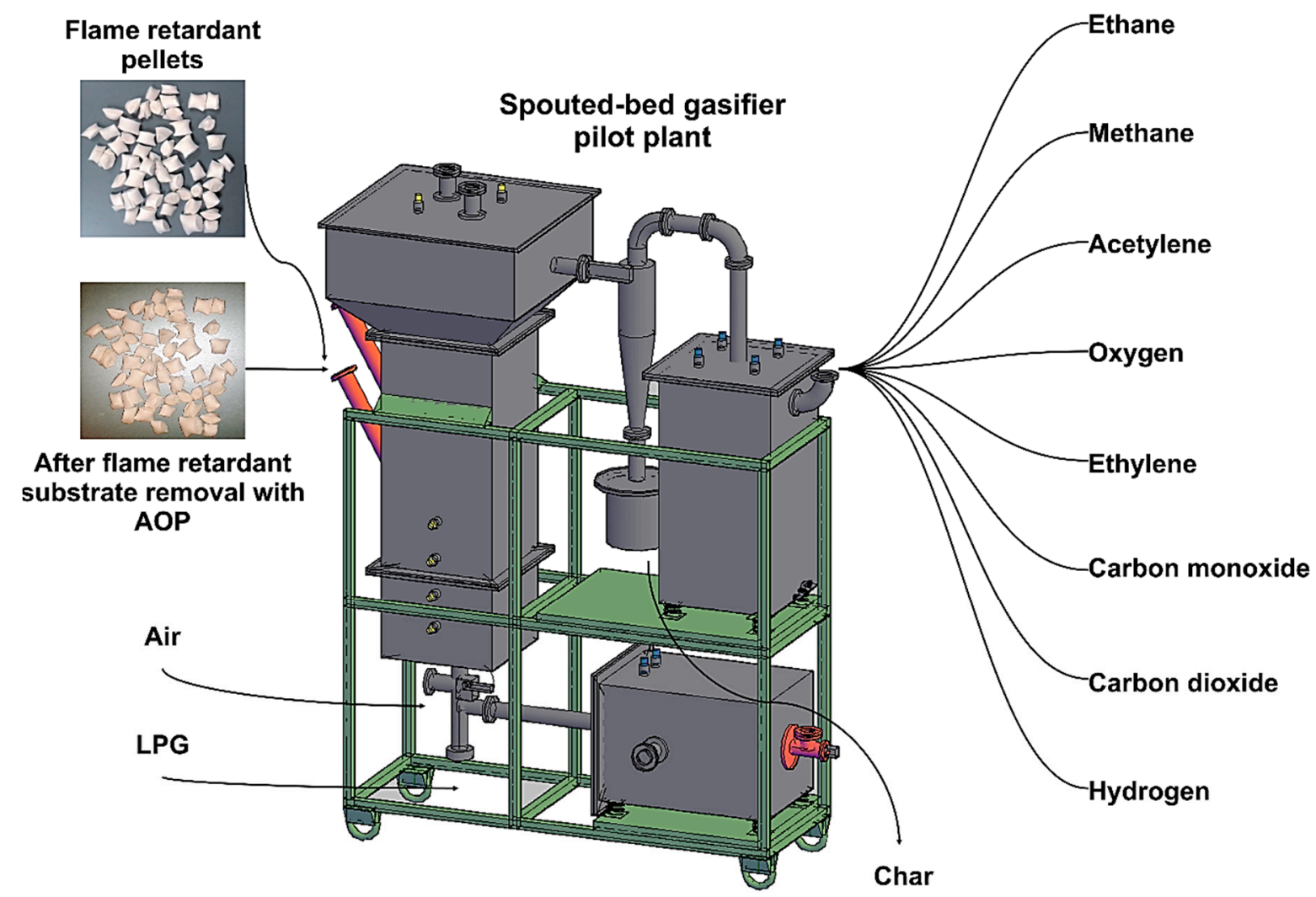

Figure 1. Schematic illustration of utilized spouted bed gasification plant and prepared pellets.

\subsection{Gasifiers Rig Temperature}

Transitory thermal in gasification requires primary temperature and time duration, consider significant parameters for the generated gas composition and its quality. To analyze the temperature distribution inside the reactor of gasifier, the flow rate of prepared textile pellets to reach a temperature above $800{ }^{\circ} \mathrm{C}$ was analyzed with thermocouples, shown in Figure 2.

The start-up of the gasification occurs in three steps: first, air and liquefied petroleum gas (LPG) is supplied $(11 \mathrm{~kW})$ with sand to reach a temperature about $350{ }^{\circ} \mathrm{C}$ while the burner is on. Second, combustion in the presence of air (excess of $\left.\mathrm{O}_{2}\right)$, wood pellets and sand $\left(350^{\circ} \mathrm{C}\right)$ to reach a temperature up to $800^{\circ} \mathrm{C}$ while the burner is off. At the last step, air (under stoichiometry condition) and the cotton pellet are introduced to have the process of pyrolysis (char) and gasification (syngas). The power of the burner was set at $11 \mathrm{~kW}$ with a surplus of air $(\lambda=1.2)$, without adding into the combustion chamber. The reactor was kept empty during the preliminary test, in order to remove excessive water/moisture. The initial increase in temperature is among TC- 1 and the thermocouples, it is related to the inactive concrete to reach the equilibrium temperature. Whereas TC-3 is located on top of the gas inlet and TC-1 works as a downstream to the static mixer [19]. 


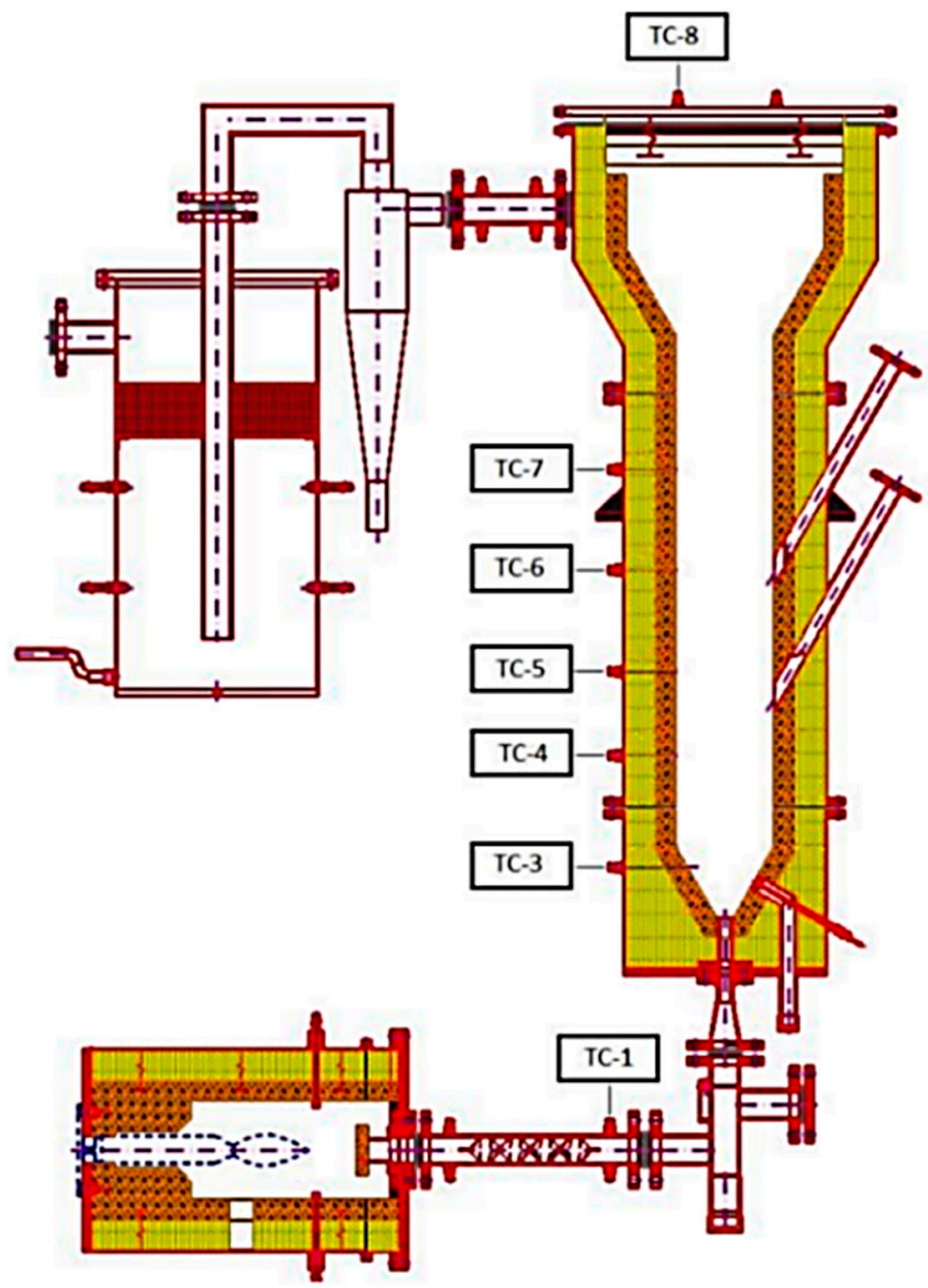

Figure 2. Thermocouples in the gasifier reactor. TC- 1 is a static mixer, TC- 3 and TC-4 are the base of the reactor, TC-5, TC- 6 , and TC-7 are mid sections of the reactor, and TC- 8 is the reactor top.

The spouted bed gasification plant is designed to operate $200 \mathrm{~g} / \mathrm{min}$ biomass with capacity of generating $20 \mathrm{~kW} / \mathrm{h}$ thermal energy. The pyramidal spouted bed reactor, is basically on past cold unit fluid dynamics $[10,19,32]$. The char particles and ashes are separated from a cyclone with a continuous streaming of material to the reactor through a scrubber. A char free gaseous stream is gathered into an analyzing system. The production of char and its evaluation were not considered in this study. However, operation activities under the regime permits mass balance conclusion over $95 \%$ [19,32]. The spouted bed is composed of inert solids to improve energy and mass transfer rates and contains up of $2 \mathrm{~kg}$ of silica sand inside the reactor. Air as gasifier agent is blown into the reactor at $40 \mathrm{Nm}^{3} / \mathrm{h}$ to fluidize the solid materials inside the reactor. The combustion chamber positioned between the reactor and air blower, pre-heats the reactor throughout the first stage of start-up with a supply of gas $[19,32]$.

\subsection{Proximate Characterization}

For accurate evaluation and enhance plant's efficiency, proximate and ultimate analysis and heating values of the biomass is essential. The basic chemical composition of the flame retardant cotton and thermos-physical properties after removal of flame retardant substrate from cotton were measured through proximate and calorimetric analysis. The moisture and ash content were determined based on standards; ISO 18134 [33] and CEN 14775 [34]. Calorimetric and elemental analyses were determined based on standards; CEN 14918 [35] and ISO 16948 [36], using ELEMENTAR Vario Macro Cube and IKA mod. C200. For elemental analysis, $1 \mathrm{~mm}$ sized samples were burnt in an oxygen/carrier gas (helium) mixture, to convert into gaseous products of combustion and ash, using instrumental 
gas analysis. The calorific value was obtained using bomb calorimeter at the reference temperature $25^{\circ} \mathrm{C}$ calibrated by the combustion of benzoic acid, the higher heating value (HHV) was calculated. The percentage content of the volatile matter contained in the sample pellets was determined using thermogravimetric analysis in a STA $449 \mathrm{~F} 3$ Jupiter Netzsch, from $25^{\circ} \mathrm{C}$ to $900{ }^{\circ} \mathrm{C}$ with a heating rate of $2{ }^{\circ} \mathrm{C} / \mathrm{min}$ in an inert atmosphere [32].

\subsection{Thermal Transitory and Syngas Characterization}

The produced gas during continuous thermal gasification varies in composition, due to a number of factors such as, the reactor temperature, the quality of the waste and the inlet gas composition. These factors are mainly responsible for the change in syngas components. It is essential to analyze gas directly rather to stock in sacks and analyze later, since substantial hydrocarbons may adsorb or condensate amid the carriage, conceding the last outcomes [19]. A continuous syngas analyzer based on a tunable filter spectroscopy (TFS), which is used to analyze the continuously produced syngas was chosen, the schematic illustration of the TFS spectroscopy is shown in Figure 3.

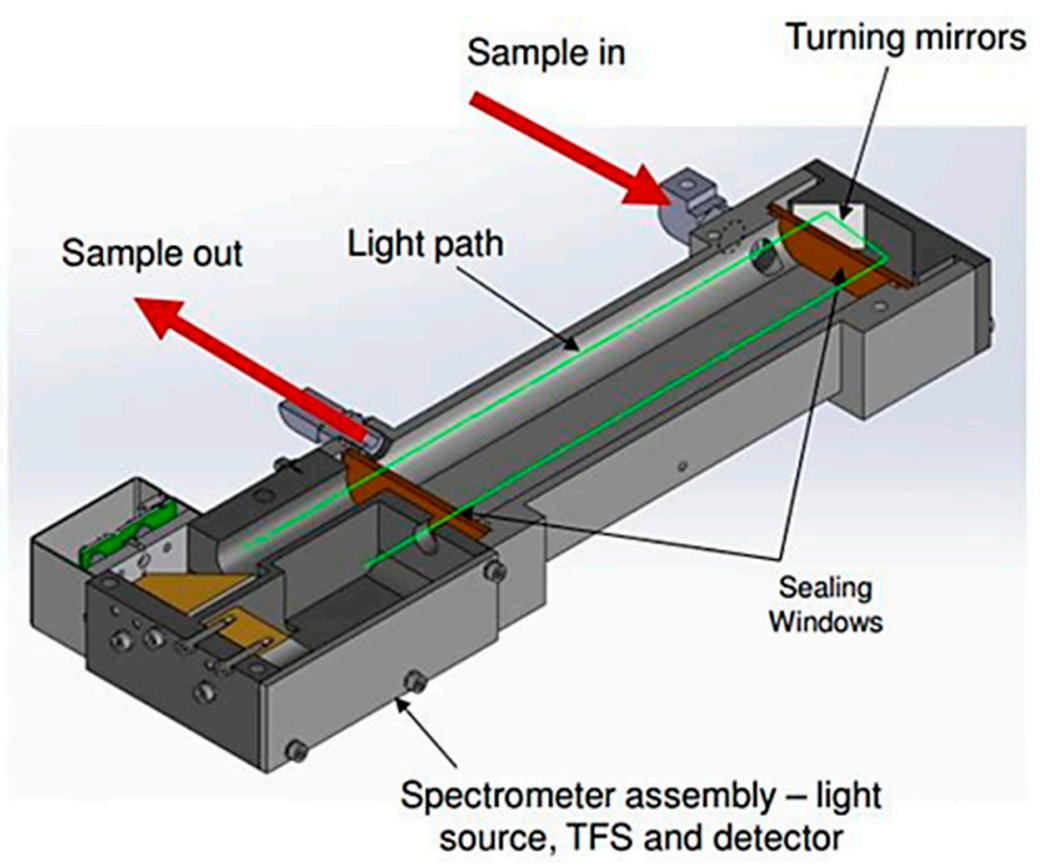

Figure 3. Schematic illustration of on-line syngas analyzer.

Principles of Syngas Analyzer (Tunable Filter Spectroscope)

TFS analyzer is based on suspended light absorption, equipped for percent to ppm level fixation checking of numerous gas mixes. It comprises of a light spectrometer, a solitary component photo-detector, a flow-through specimen cell and the supporting gadgets. The spectrometer supplies wavelength examination with high optical throughput. The magnitude of absorption can indicate the quality of an element of gas atoms, by a known wavelength, temperature and weight. Later this magnitude of spectra absorption is used to compute volumetric concentrations. TFS permits constant examination to get gas compositions every 5 seconds [19].

\section{Results}

\subsection{Proximate Analytics}

Table 1 shows the main properties of flame retardant pellets before and after the removal of flame retardant substrate, taking pure cotton as reference (in dry basis). The moisture content of 
flame retardant cotton was found to be $2.43 \%$ and $2.63 \%$ before and after the removal of flame retardant substrate.

Table 1. Proximate analysis and calorific values of prepared pellets for gasification.

\begin{tabular}{cccc}
\hline Analytics [g/g (wt. \%)] & Pure Cotton & $\begin{array}{c}\text { Cotton with Flame } \\
\text { Retardant }\end{array}$ & $\begin{array}{c}\text { Cotton after Flame } \\
\text { Retardant Removal }\end{array}$ \\
\hline Moisture content & 8.43 & 2.42 & 2.63 \\
\hline Ash & 1.84 & 2.79 & 0.46 \\
\hline C & 44.45 & 42.41 & 43.88 \\
\hline H & 6.34 & 6.28 & 6.29 \\
\hline O & 47.12 & 47.01 & 48.35 \\
\hline N & 0.10 & 1.12 & 0.88 \\
\hline S & 0.19 & 0.36 & 0.12 \\
\hline $\begin{array}{c}\text { Higher heat value (HHV, } \\
\text { MJ/kg) }\end{array}$ & 15.88 & 16.26 & 15.70 \\
\hline
\end{tabular}

\subsection{Thermal Transitory and Gasification Temperature}

Preliminary experimentation using wood pellets was carried out with different LPG/air ratios to create a feasibility reaction, under controlled operations (combustion, pyrolysis or gasification). Generally, the initial stage involves the pre-heating of spouted bed, which occurs around $350{ }^{\circ} \mathrm{C}$. The furnace thermal power was set at $11 \mathrm{~kW} / \mathrm{h}$ with a minimal extra-stoichiometric air and suitable LPG flow rate [10]. Achieving this temperature assures the ignition point of prepared flame retardant cotton pellets.

In order to attain the gasification phase, it is important to maintain high temperature. The temperature increment should expand progressively in the gasification plant, in order to expel the excess water/moisture present in the solid matrix. Sometimes, this operation takes up to a few hours and ought to revise for various cycles. The pre-heating temperature inside the reactor for gasification was reached to about $350^{\circ} \mathrm{C}$ at $11 \mathrm{~kW}$ in $60 \mathrm{~min}$, with a continuous but imitated addition of amounts of wood pellets (to avoid wastage of prepared pellets). High oxidizing atmosphere $(\lambda \approx 1.20$, the stoichiometry ratio between gaseous fuel and oxygen) for total combustion of fed material, provides an additional energetic boost and enthalpy of the reaction inside the rig triggering immediate temperature increase [19]. Attaining the high temperatures, prepared flame retardant cotton pellets were fed.

As shown in Figure 4, gasification of both the fed materials, flame retardant cotton pellets (before and after degradation) are in a regime of low-temperature gasification. The high-temperature gasification occurs at $\sim>1200{ }^{\circ} \mathrm{C}$, while $\sim<1000{ }^{\circ} \mathrm{C}$ is considered as low-temperature gasification. In low-temperature gasification, air is utilized as gasifying medium, at times leads to undesired nitrogen into the generated gas [37]. 


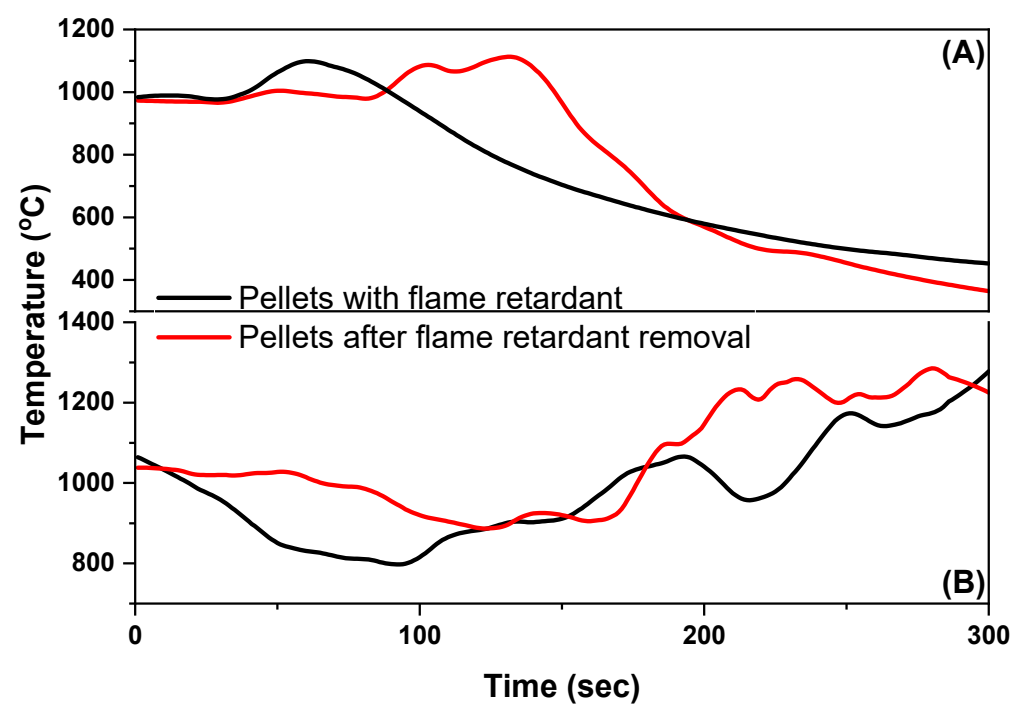

Figure 4. Transitory temperature curve for (A) sand (TC-3) and (B) fountain (TC-4) of cotton textile pellets with and after flame retardant substrate removal.

\subsection{Gas Evolution from Gasified Textile Pellets}

\subsubsection{Flame Retardant Cotton}

The compositions of gas generated from the gasification of the flame retardant cotton fabric (before and after the removal of flame retardant substrate) were found in-line with the sample from the off-gas piping line. The transport between incessant sampling and gas analysis took $60 \mathrm{~s}$. Later, gas composition converted from the mass flow rate through total gas flow rate and measured component calculations. The gas composition was analyzed for major components like $\mathrm{CO}, \mathrm{CO}_{2}, \mathrm{H}_{2}$ and $\mathrm{CH}_{4}$.

During gasification, evolution of other components, the heavier hydrocarbons for instance, along with carbon monoxide $(\mathrm{CO})$ and hydrogen $\left(\mathrm{H}_{2}\right)$ was utmost considered [37]. Heavier hydrocarbons are broken further into additional components and used for various other applications. In Figure 5 volatile components $\mathrm{CH}_{4}$, ethane, acetylene, ethylene, $\mathrm{CO}, \mathrm{CO}_{2}, \mathrm{H}_{2}$ and $\mathrm{CH}_{4}$ are shown from the gas compositions evolved from the gasification of flame retardant cotton pellets.

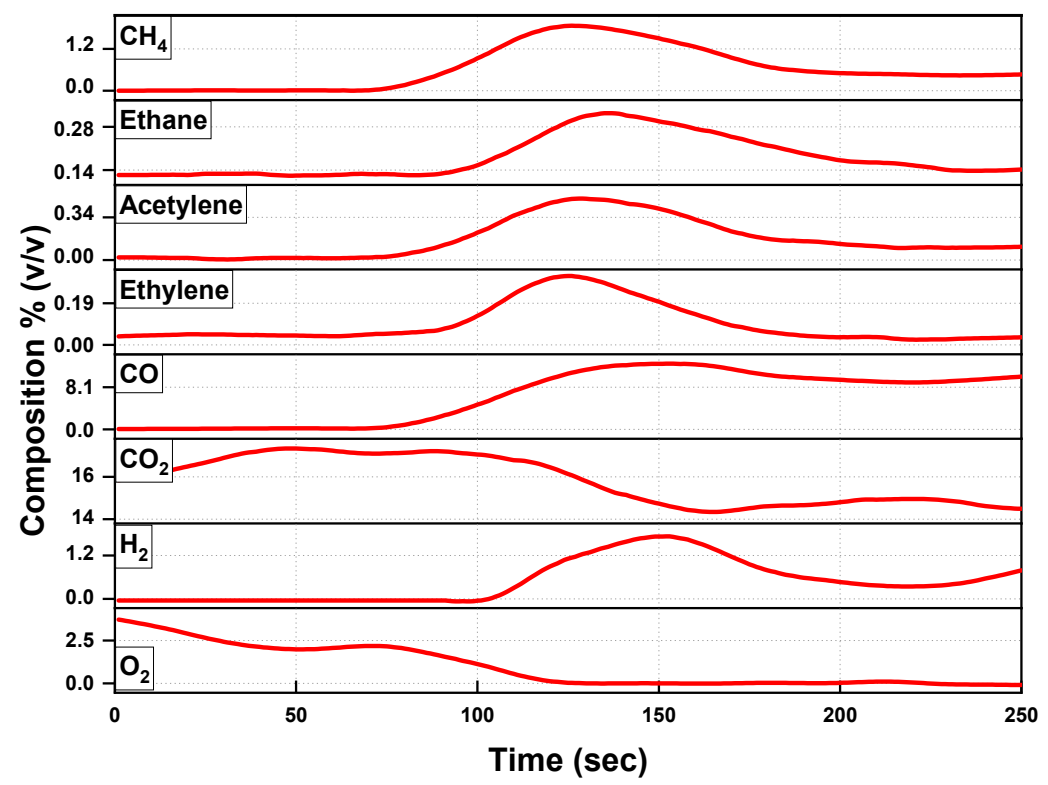

Figure 5. Evolved components in the gas composition from the gasification of flame retardant cotton pellets. 


\subsubsection{Cotton after Flame Retardant Removal}

Numerous components present in the developed gas from the gasification process are linked to different factors, which can influence the results of evolved gas. During the elevation of gasification temperatures for instance, components such as $\mathrm{H}_{2} \mathrm{O}, \mathrm{CO}_{2}, \mathrm{CH}_{4}$ and other low-molecular-weight gasses continue to increase.

The combustion of flame retardant cotton with phosphorus and nitrogen elements perhaps start with a catalyze reaction of dewatering, decarboxylation, and charring [38]. The flame retardant substrate on cotton textile resist complete combustion. Similarly, gasifying flame retardant on cotton hinders gas evolution and fragmented products. To obtain a quality gas composition with minimum impurities and maximum energetic conversion efficiency, the optimized parameters and conditions for gasification of textiles are vital.

The optimal flow rate of particular shape and sized flame retardant cotton textile was found at $150 \mathrm{~g} / \mathrm{min}$ for gasification. The flow rate was made starved occasionally to avoid overfeeding and plugging of pellets, which resulted in an irregular gas yield at variant places. Figure 6 shows non-constant gas yield due to rutted feeding of low-density fibrous cellulosic material into the designed small-scale gasification pilot unit. In given context, the gas yield with averaged composition values was calculated that will be discussed in the following section.

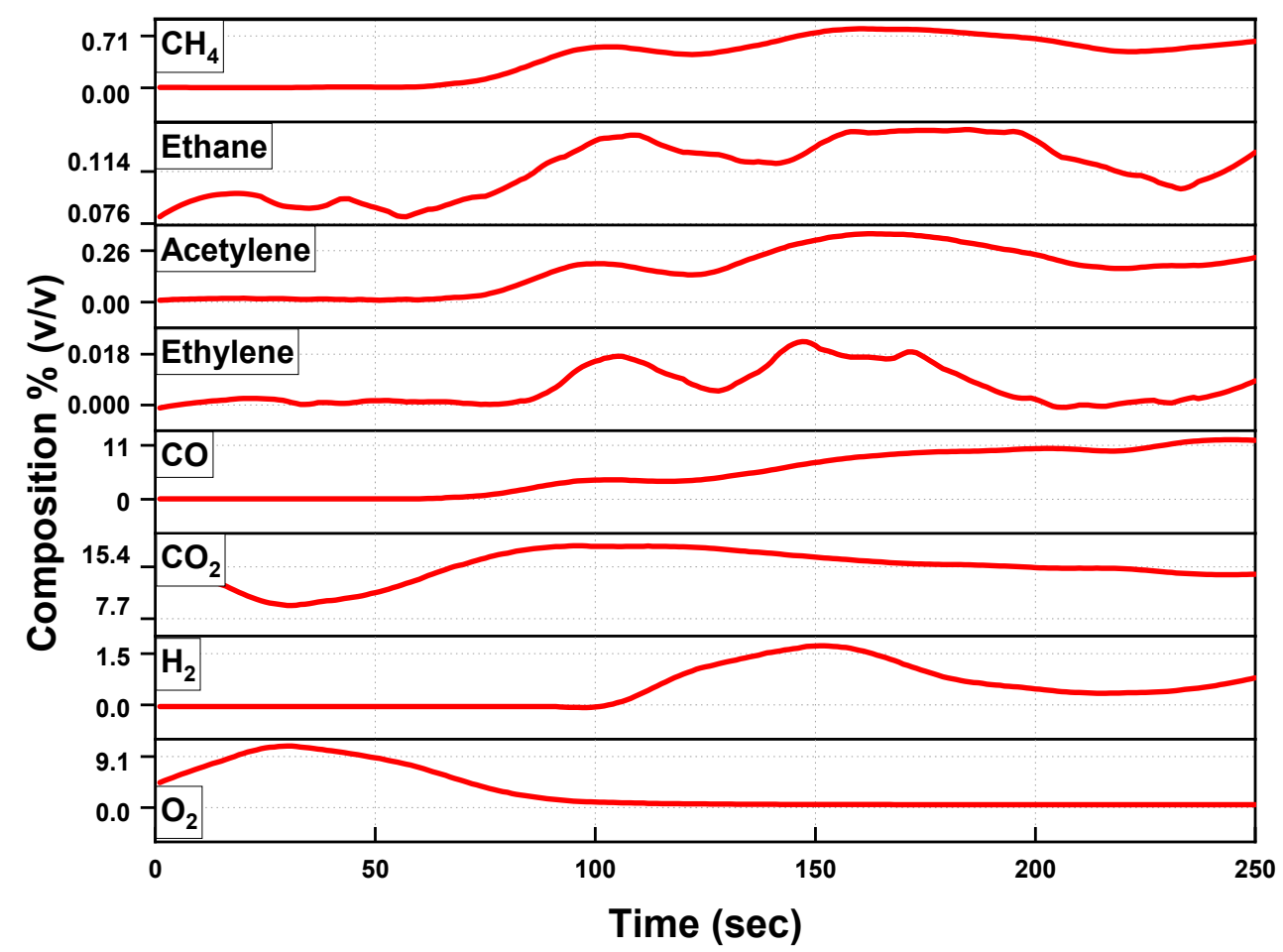

Figure 6. Evolved components in the gas composition from the gasification of flame retardant cotton pellets after flame retardant removal.

Figure 7 shows the gas yield composition as a function of gasification temperature at the theoretical equivalence ratio of two samples. Carbon dioxide $\left(\mathrm{CO}_{2}\right)$ yield higher in both samples, but gets slightly lower in the sample with removed flame retardant substrates as the temperature increased Figure 7B. Carbon monoxide $(\mathrm{CO})$ and methane $\left(\mathrm{CH}_{4}\right)$ yield was higher in flame retardant cotton at initial temperatures compared to ones with removed flame retardant, probably as of irregular feeding system. Whereas other components of evolved gas were in lower contents on both samples, the average gas yield components are discussed below. The concentration of acetylene $\left(\mathrm{C}_{2} \mathrm{H}_{2}\right)$ and ethylene $\left(\mathrm{C}_{2} \mathrm{H}_{4}\right)$ was in slightly low quantity in both samples from low to high temperatures. Oxygen $\left(\mathrm{O}_{2}\right)$ was higher in the sample with flame retardant substrate removed. 

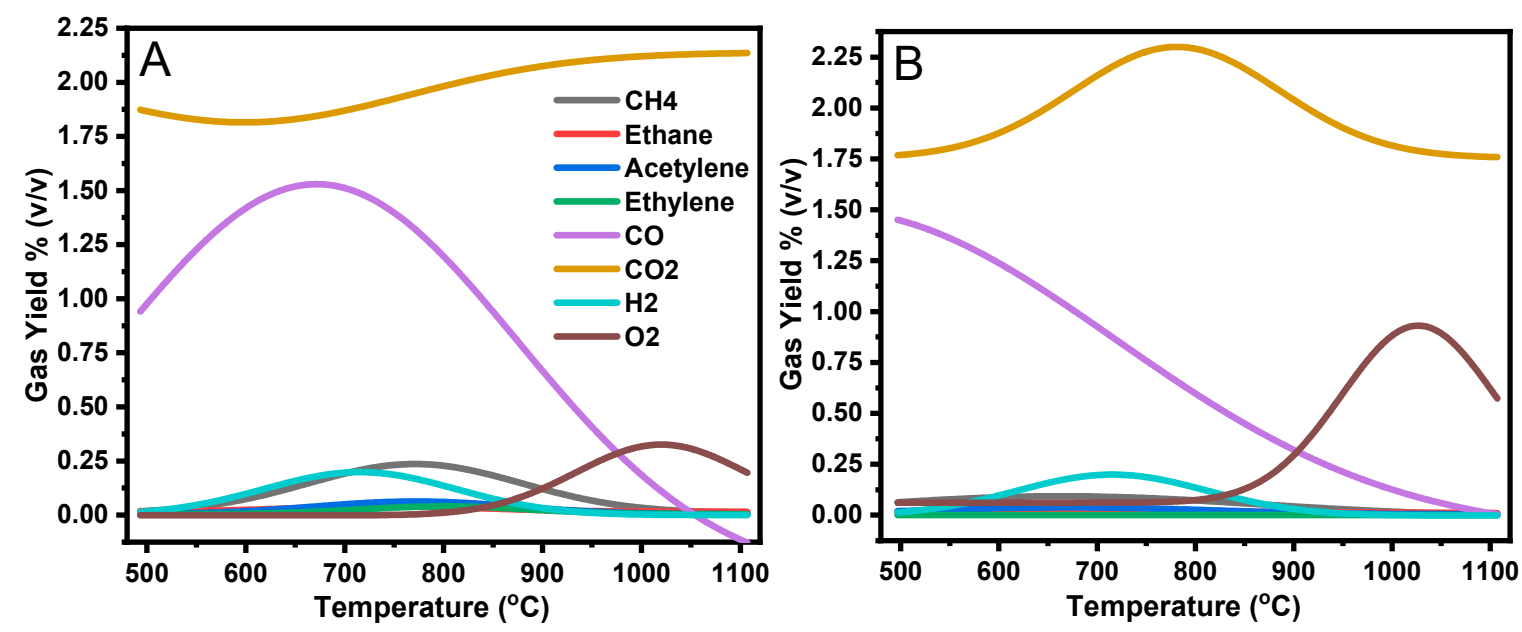

Figure 7. Gas yield composition as a function of gasification temperature at the theoretical equivalence ratio of $0.48 \pm 0.05$ for (A) flame retardant cotton and (B) $0.46 \pm 0.02$ after flame retardant substrate removal.

\section{General Discussion}

The moisture content in pure cotton is the highest, and the lowest in flame retardant cotton. While after the removal of the flame retardant substrate, the moisture content increased compared to the flame retardant cotton. The water/moisture content is important in terms of thermal valorization and conversion efficiency of burnt material, high water content lowers the calorific value [39]. The high moisture content and relatively high carbon value, and an increase of other volatile matter compared to the total composition, make the samples a good candidate for oxidation and gasification processes and have a positive impact on biomass reactivity, ultimately [40]. For proximate analysis, residue of each sample burnt was determined as the ash, and carbon content was estimated [41]. The residue content or ash also affects the calorific values while combustion. The higher the ash content, the lower the calorific value and volatile matters will be. After the removal of the flame retardant substrate, decreased ash content of the material can be seen in Table 1. In addition, the content of the volatile materials is increased after the removal of the flame retardant from cotton, as it determines the combustion ability of the material. A material with the high volatile matter content would enhance the calorific values, due to the vapor combustion [39]. Moreover, a decrease in the amount of ash content, is useful to avoid fouling, corrosion and slag formation while gasification [42].

Recently, the thermal valorization from non-conventional resources gained attention to reduce domestic and industrial waste and save fossil fuels. Besides, waste management is getting fussier with the increase in the amount of waste and routes of waste [43]. For instance, with a huge increase in plastic production and consumption, only $10 \%$ of the plastic waste generated is recycled world-wide [44]. Moreover, $20 \%$ of the world-wide plastic wastes (4 to 12 million metric tons) entered water environment, river and marine [45]. This enhances the importance of sustainable waste treatment techniques. Gasification is a valuable method to convert biomass and organic waste into the multiuse gas (syngas). A customized spouted bed with an unusual geometry developed for an easier scale-up, provides better understanding of the gasification process. Due to functional design and availability for low gas flow rate and pressure can drop lower than bubbling fluidization, the spouted bed has better hydrodynamic controls. Moreover, reaching a stationary thermal state is one of the major parameters of gasification plants. The temperature inside the reactor was increased gradually in order to remove excess water and humidity, and avoid thermal shocks and fractures in the concrete matrix.

Two stage start-up was carried out for the thermal state, initially propane was burned in a burner $(11 \mathrm{~kW})$ with minimal extra-stoichiometric air, which reached at $350{ }^{\circ} \mathrm{C}$ in about $45 \mathrm{~min}$. The wood pellet at $50 \mathrm{~g} / \mathrm{min}$ were introduced and burned to reach the actual gasification temperature (around 900-950 ${ }^{\circ} \mathrm{C}$ ), ultimately in $90-110 \mathrm{~min}$ [32]. The prepared pellets were then fed. Figure 8 shows the 
start-up thermal profile and pre-heating stages with increases in temperature with the introduction of pellets.

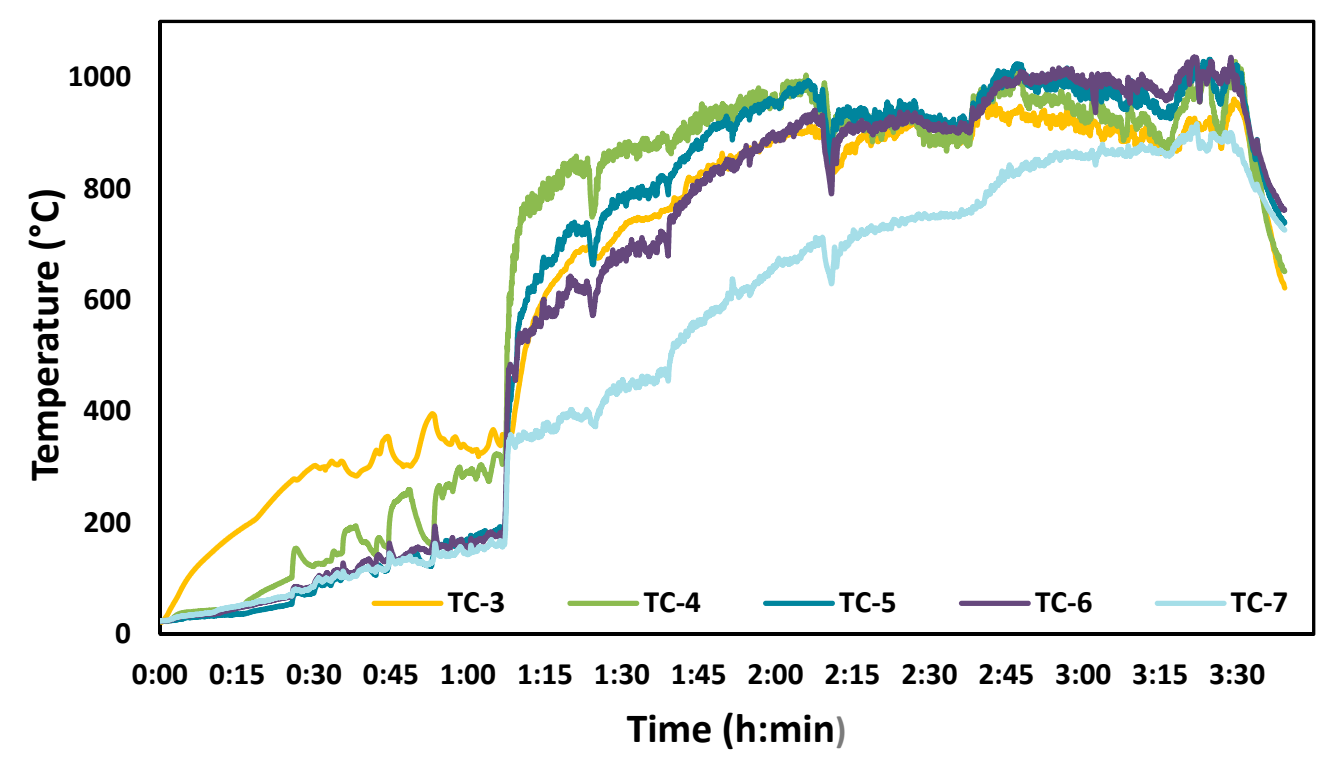

Figure 8. Thermal profile inside the gasification plant during the start-up (TC-3 (bed), TC-4 (fountain), TC-5 (middle 1), TC-6 (middle 2), and TC-3 (middle 3)).

Cellulose textiles go through two thermal processes when being burned, namely combustion and pyrolysis. Combustion deals the oxidation process and consumes solids, liquids and flammable gases from the brunt material. The produced residues in the pyrolysis, which is the second thermal process, result in heat surplus. Dewatering and charring of cellulose take place in pyrolysis, and produce water, carbon dioxide and other solid residues. Non-volatile l-glucose (liquid) is produced from cellulosic materials, by de-polymerization, and in the presence of oxygen decomposed l-glucose is further oxidized (fire) to generate heat energy [46]. In opposite, the mere purpose of flame retardant is to resist the oxidization process of the material it applied to, suppressing rapid combustion and slow down the flame spreading. In addition, flame retardants defer incomplete combustion of material fed into gasifier, withal results in increased auxiliary stimulants concentration [47]. In addition, pyrolysis of flame retardant is found to produce abundant toxic organic matters, with the complex compositions which are difficult to purify and utilize [48]. Cellulose generates flammable fragments while undergoing thermal decomposition, ketones, aldehydes, furans, furfural, and mucleoglucosan are produced, a flame retardants for cellulosic materials, however, acts as gas a scavenging agent, giving off fewer gaseous products $[46,49]$.

The starting air inflow showed stable spouting conditions at $30 \mathrm{~m}^{3} / \mathrm{h}$ in a bed of sand at $25 \mathrm{~cm}$ (room temperature). Attaining air inflow $17 \mathrm{~m}^{3} / \mathrm{h}$, which is necessary to satisfy the fluid dynamic requirements of the reactor. Here two types of material (biomass) were considered, flame retardant cotton and cotton after flame retardant substrate removal were tested as a function of gasification temperature at a theoretical equivalence ratio (ER). ER being an important design parameter for a gasifier is defined as the ratio between actual air $\left(\mathrm{O}_{2}\right)$ entering to the system and the required air $\left(\mathrm{O}_{2}\right)$ to complete the stoichiometric combustion, and can be calculated by the following given function (Equation (1)) [37].

$$
E R=\frac{\text { Actual air }}{\text { Stoichiometric air }}=E A
$$

ER is excess air coefficient and should be $>0.1$, whereas the proximation of ER for thermal valorization of a material lies in, $(E R \sim 0)$ for pyrolysis, $(0<E R<1)$ for gasification, and $(E R \geq 1)$ combustion in the continuum region [50]. The stoichiometric quantity of air, which can be based on the proximate analysis of the material fed (see Table 1). At low ER values, char is not converted into 
gases completely and give off higher tar contents. For instance, at an ER $<0.25$, produced gases burn which increase the temperature, while ER $>1.0$ shows the material is combusted rather than is gasified. Thus ER values defines the gas quality [26]. However, the preparatory system with low biomass flow could not reach an ER lower than $0.46 \pm 0.02$ (Figure 7). Despite the fact, with future upgrades to the solid feeding system, it could reach an even lower ER. Char not being the main product of spouted bed gasification, was not considered as it could not be obtained in pure gasification conditions ER > $0.46 \pm 0.02$ and a feed rate at $150 \mathrm{~g} / \mathrm{m}$. Nonetheless, the preparatory study of flame retardant cotton after flame retardant substrate removal as biomass feed, gasified at lower ER value compared to flame retardant cotton $(0.48 \pm 0.05)$. The contribution of ER at certain temperature reduces the mass fraction of $\mathrm{CO}$, at the stake of increased $\mathrm{CO}_{2}$ [51], which can be seen clearly in Figure 7. At lower ER values, the material produces more $\mathrm{CO}$ to the system at the expense of $\mathrm{CO}_{2}$, whereas high ER values convert $\mathrm{CO}$ into $\mathrm{CO}_{2}$ [52]. Gas yield of other contents, $\mathrm{H}_{2}, \mathrm{CH}_{4}$ and $\mathrm{O}_{2}$ was high in one and low in the other sample, this fluctuation of curves is possibly due to air flow taken as a variable and its average was taken compute ER or shape variation in prepared textile pellet and wood chips. Such phenomenon has also been found to affect the experimental results [51].

Table 2 shows a moderate variation in gas components evolved from gasification of flame retardant cotton and after the removal of flame retardant substrates with Fenton's reaction. With a manual fluidification of flame retardant cotton textile pellets, initiated by feeding wood pellets to attain the gasification temperature this perhaps led to irregular gas composition. Beds of the spouted bed gasifiers are made up of fine particles, where produced gas instead ascend through predefined spout in the center, goes through whole bed in a big bubble form [26]. Which is known as slugging and generally cause instability in spouted beds but can be refined with fountain alterations [53]. The irregular gas evolution outcomes with mass flow rate are obvious in Figure 6. However, thermal valorization by gasification of flame retardant textile products is achievable under standard and controlled conditions.

Table 2. Averaged gas composition values evolved from the gasification.

\begin{tabular}{cccccccc}
\hline \multirow{2}{*}{ Cotton Pellets } & \multirow{2}{*}{$\begin{array}{c}\text { Flow Rate } \\
(\mathbf{g} / \mathbf{m i n})\end{array}$} & \multicolumn{2}{c}{ Temperature $\left({ }^{\circ} \mathrm{C}\right)$} & \multicolumn{4}{c}{ Gas Composition \% $(\boldsymbol{v} / \mathrm{v})$} \\
\cline { 3 - 8 } & & Annulus & Fountain & $\mathbf{C H}_{\mathbf{4}}$ & $\mathbf{C O}$ & $\mathbf{C O}_{\mathbf{2}}$ & $\mathbf{H}_{\mathbf{2}}$ \\
\hline $\begin{array}{c}\text { Flame retardant } \\
\text { After flame retardant }\end{array}$ & 150 & 750 & 983 & 1.8 & 12.2 & 15.8 & 1.8 \\
substrate removal & 150 & 781 & 1064 & 0.8 & 12.1 & 15.33 & 1.85 \\
\hline
\end{tabular}

The values were calculated under the conditions of: silica sand (2 L), fluidization with air at $17 \mathrm{Nm}^{3} / \mathrm{h}$ and bed inert material.

Nevertheless, the average reactor temperature (annulus) for flame retardant cotton after removal of flame retardant substrate is higher, posing improved combustion/gasification. The cotton textile treated with organophosphorus flame retardant has lower decomposition temperatures because of the catalyzed dehydrations by phosphorus acid on cellulose [54]. This occurrence leads to the incomplete combustion of cellulosic materials with organophosphorus substrates. Low gasification temperature, which is due to organophosphorus substrate of flame retardant has phosphorus and nitrogen active elements, affects pyrolysis reactions of cellulose while burning. After the removal of flame-retardant substrate from cotton, the gasification temperature increased.

The flame retardant substrate decomposes and generates phosphoric acid, later it polymerizes to polyphosphoric acids at lower temperatures. The acids catalyze the hydroxyl groups of cellulose to dehydrate and carbonize, limiting the pyrolysis reactions [46]. So the production of water, carbon dioxide and other residues increases. At the same time, the production of combustible fragments particularly ketone, aldehyde, ether and ester is reduced. It also affects the mass to energy conversion, as flame retardant has the tendency to lower the decomposition temperature of substrate, favoring carbonization instead de-polymerization of the macromolecules, ultimately results in greater char yield. It is required fewer volatile materials for gas phase combustion [23]. The removal or degradation 
of flame retardant substrate from cellulose alters the pyrolytic properties, reverting to its original cellulosic properties.

The conversion of material or biomass by fractional oxidation into a gas composition, consisting of $\mathrm{CH}_{4}, \mathrm{H}_{2}, \mathrm{CO}$ and $\mathrm{CO}$ in gasification also requires oxidants, which can be either stream, air, $\mathrm{O}_{2}$, and $\mathrm{CO}_{2}$ or their mixtures sometimes. The oxidant type is considered as a main parameter in gas composition. Air is the mostly used as a gasifying agent for its zero cost. Steam is also preferred for its advantages as $\mathrm{H}_{2}$ content in produced syngas and increased heating value [55].

\section{Conclusions}

Evidently, utilization of flame retardants in the textile industry to suppress rapid combustion is increasing each year. Their waste treatments are hindered by leachate if landfilled and less energetic yields due to incomplete combustion when incinerated. Considering the thermal valorization and resource depletion, technical textiles potentially can be used instead untreated cellulosic biomass in gasification. In the case of flame retardant cotton pellets, the gasification temperature stabilized at $750{ }^{\circ} \mathrm{C}$ annulus and $983^{\circ} \mathrm{C}$ fountain in the reactor. After the removal of flame retardant, the gasification temperature increased to $781^{\circ} \mathrm{C}$ and $1064^{\circ} \mathrm{C}$ annulus and fountain respectively. The increase in the calorific values and syngas gas components was seen as well. Proximate analysis showed relatively high volatile contents and increased moisture, and lowered carbon concentrations compared to flame retardant cotton samples. The calorimetric analysis of samples, retaining the HHV values after degradation of flame retardant substrate illustrate its usability instead of pure cotton. Furthermore, prior to valorization, degradation and removal of flame-retardant substrate from cellulosic textiles were found to enhance gasification parameters. Having said that, detailed analytical studies on tar and vaporization of flame retardant substrates during thermal valorization are needed, which seems missing in literature.

Author Contributions: Conceptualization, S.Y.; methodology, S.Y. and M.C.; validation, G.R. and D.S.; formal analysis and investigation, S.Y. and M.C.; writing-original draft preparation, S.Y., M.C., M.H. and D.S.; writing-review and editing, S.Y., D.S.; supervision, G.R. and D.S.; project administration, D.S. All authors have read and agreed to the published version of the manuscript.

Funding: The APC was funded by Commonwealth Rutherford Fellow funded by Government Department for Business, Energy and Industrial Strategy (BEIS) through the Commonwealth Scholarship Commission in the United Kingdom, under the Project Code: E17R00076.

Acknowledgments: The author S.Y. acknowledge the European Commission's program SMDTex within the framework Erasmus Mundus.

Conflicts of Interest: The authors declare no conflicts of interest.

\section{References}

1. Allesina, G.; Pedrazzi, S.; Allegretti, F.; Morselli, N.; Puglia, M.; Santunione, G.; Tartarini, P. Gasification of cotton crop residues for combined power and biochar production in Mozambique. Appl. Therm. Eng. 2018, 139, 387-394. [CrossRef]

2. EURATEX the EU-28 Textile and Clothing Industry in the year 2017; European Apparel and Textile Confederation: Bruxelles, Belgium. Available online: http://euratex.eu/fileadmin/user_upload/documents/key_data/fact_ and_figures_2017LR.pdf (accessed on 2 December 2017).

3. EURATEX EURATEX Released Bulletin $N^{\circ}$ 2; European Apparel and Textile Confederation: Bruxelles, Belgium. Available online: http://euratex.eu/fileadmin/user_upload/images/press_releases/presse_2018/Press_Release_ EURATEX_BULLETIN_2-2018.pdf (accessed on 2 December 2018).

4. Yasin, S.; Behary, N.; Curti, M.; Rovero, G. Global Consumption of Flame Retardants and Related Environmental Concerns: A Study on Possible Mechanical Recycling of Flame Retardant Textiles. Fibers 2016, 4, 16. [CrossRef]

5. ISI Worldwide flame retardants market to reach 2.8 million tonnes in 2018. Addit. Polym. 2015, 2015, 11. 
6. Yasin, S.; Behary, N.; Giraud, S.; Perwuelz, A. In situ degradation of organophosphorus flame retardant on cellulosic fabric using advanced oxidation process: A study on degradation and characterization. Polym. Degrad. Stab. 2016, 126, 1-8. [CrossRef]

7. Yasin, S.; Parag, B.; Nemeshwaree, B.; Giorgio, R. Optimizing Organophosphorus Fire Resistant Finish for Cotton Fabric Using Box-Behnken Design. Int. J. Environ. Res. 2016, 10, 313-320.

8. Yasin, S.; Curti, M.; Behary, N.; Perwuelz, A.; Giraud, S.; Rovero, G.; Guan, J.; Chen, G. Process Optimization Of Eco-Friendly Flame Retardant Finish For Cotton Fabric: A Response Surface Methodology Approach. Surf. Rev. Lett. 2017, 24, 1750114. [CrossRef]

9. Yasin, S.; Behary, N.; Giraud, S.; Perwuelz, A.; Rovero, G. Degradation of Phosphorus Based Flame Retardant by IR Radiation; AUTEX: Iasi, Romania, 2015.

10. Yasin, S.; Massimo, C.; Rovero, G.; Behary, N.; Perwuelz, A.; Giraud, S.; Migliavacca, G.; Chen, G.; Guan, J. An alternative for the end-of-life phase of flame retardant textile products: Degradation of flame retardant and preliminary settings of energy valorization by gasification. BioResources 2017, 12, 5196-5211. [CrossRef]

11. Yasin, S.; Behary, N.; Perwuelz, A.; Guan, J. Life cycle assessment of flame retardant cotton textiles with optimized end-of-life phase. J. Clean. Prod. 2018, 172, 1080-1088. [CrossRef]

12. Yasin, S.; Sun, D. Propelling textile waste to ascend the ladder of sustainability: EOL study on probing environmental parity in technical textiles. J. Clean. Prod. 2019, 233, 1451-1464. [CrossRef]

13. Zhang, T.; Fiedler, H.; Yu, G.; Ochoa, G.S.; Carroll Jr, W.F.; Gullett, B.K.; Marklund, S.; Touati, A. Emissions of unintentional persistent organic pollutants from open burning of municipal solid waste from developing countries. Chemosphere 2011, 84, 994-1001. [CrossRef]

14. Horrocks, A.R.; Eivazi, S.; Ayesh, M.; Kandola, B. Environmentally sustainable flame retardant surface treatments for textiles: The potential of a novel atmospheric plasma/UV laser technology. Fibers 2018, 6, 31. [CrossRef]

15. McAllister, D.L. Brominated Flame Retardants: Current Issues and Future Prospects; Interscience Communications: London, UK, 1992.

16. Ni, H.-G.; Lu, S.-Y.; Mo, T.; Zeng, H. Brominated flame retardant emissions from the open burning of five plastic wastes and implications for environmental exposure in China. Environ. Pollut. 2016, 214, 70-76. [CrossRef] [PubMed]

17. Fiani, E.; Umlauf, G.; De Assunção, J.V.; Kakareka, S.; Fiedler, H.; Costner, P.; Weber, R. Toolkit for Identification and Quantification of Releases of Dioxins, Furans and Other Unintentional POPs; UNEP: Geneva, Switzerland, 2013; pp. 51-52.

18. Yasin, S.; Sun, D. Critical Review on the Waste-to-Energy Techniques for Flame Retardant treated Textiles. In Proceedings of the ISER 529th International Conference on Agricultural and Biological Science, Bali, Indonesia, 13-14 February 2019.

19. Massimo, C. Solids and Gas Hydrodynamic Characteristics in Square-Based Spouted Beds for Thermal Applications; Politecnico di Torino: Torino, Italy, 2015.

20. Yasin, S. Eco-design for end-of-life phase of flame retardant textiles. Ph.D. Thesis, Université Lille 1-Sciences et Technologies, Villeneuve-d'Ascq, France, 2017.

21. Jonkers, N.; Krop, H.; van Ewijk, H.; Leonards, P.E. Life cycle assessment of flame retardants in an electronics application. Int. J. Life Cycle Assess. 2016, 21, 146-161. [CrossRef]

22. Yasin, S.; Behary, N.; Perwuelz, A.; Guan, J.P.; Chen, G.Q. Degradation Kinetics of Organophosphorus Flame Retardant from Cotton Fabric. Proc. Appl. Mech. Mater. Trans. Tech. Publ. 2017, 864, 54-58. [CrossRef]

23. Pandey, A.; Bhaskar, T.; Stöcker, M.; Sukumaran, R. Recent Advances in Thermochemical Conversion of Biomass; Elsevier: Amsterdam, The Netherlands, 2015.

24. Erkiaga, A.; Lopez, G.; Amutio, M.; Bilbao, J.; Olazar, M. Syngas from steam gasification of polyethylene in a conical spouted bed reactor. Fuel 2013, 109, 461-469. [CrossRef]

25. Lopez, G.; Erkiaga, A.; Amutio, M.; Bilbao, J.; Olazar, M. Effect of polyethylene co-feeding in the steam gasification of biomass in a conical spouted bed reactor. Fuel 2015, 153, 393-401. [CrossRef]

26. Tellabide, M.; Estiati, I.; Pablos, A.; Altzibar, H.; Aguado, R.; Olazar, M. New operation regimes in fountain confined conical spouted beds. Chem. Eng. Sci. 2020, 211, 115255. [CrossRef]

27. Kumar, A.; Jones, D.D.; Hanna, M.A. Thermochemical biomass gasification: A review of the current status of the technology. Energies 2009, 2, 556-581. [CrossRef] 
28. Cortazar, M.; Lopez, G.; Alvarez, J.; Amutio, M.; Bilbao, J.; Olazar, M. Behaviour of primary catalysts in the biomass steam gasification in a fountain confined spouted bed. Fuel 2019, 253, 1446-1456. [CrossRef]

29. Moliner, C.; Marchelli, F.; Bosio, B.; Arato, E. Modelling of spouted and spout-fluid beds: Key for their successful scale up. Energies 2017, 10, 1729. [CrossRef]

30. James, A.M.; Yuan, W.; Boyette, M.D.; Wang, D. The effect of air flow rate and biomass type on the performance of an updraft biomass gasifier. BioResources 2015, 10, 3615-3624. [CrossRef]

31. Yasin, S.; Curti, M.; Rovero, G. Waste management of flame retardant textiles: An alternate end-of-life design for flame retardant textile products. In Proceedings of the LCA Waste; Engineering Conferences International (ECI), Calabria, Italy, 5-10 June 2016.

32. Bove, D.; Moliner, C.; Curti, M.; Baratieri, M.; Bosio, B.; Rovero, G.; Arato, E. Preliminary tests for the thermo-chemical conversion of biomass in a spouted bed pilot plant. Can. J. Chem. Eng. 2019, 97, 59-66. [CrossRef]

33. ISO Solid Biofuels-Determination of Moisture Content-Oven Dry Method-Part 2: Total Moisture-Simplified Method. 2015. Available online: www.iso.org/standard/61539.html (accessed on 28 January 2020).

34. CEN Solid Biofuels-Determination of Ash Content, 14775:2010; European Committee for Standardization: Brussels, Belgium, 2010.

35. CEN Solid Biofuels-Determination of Calorific Value, 14918-2010; European Committee for Standardization: Brussels, Belgium, 2010.

36. ISO. Solid Biofuels-Determination of Total Content of Carbon, Hydrogen and Nitrogen-Instrumental Methods; SIS-CEN/TS 15104: Stockholm, Sweden, 2006.

37. Basu, P. Biomass Gasification, Pyrolysis and Torrefaction: Practical Design and Theory; Academic Press: New York, NY, USA, 2013.

38. Wu, W.; Yang, C.Q. A comparative study of different organophosphorus flame retardant agents for cotton: Part II: The fabric flammability and physical properties. Polym. Degrad. Stab. 2007, 92, 363-369. [CrossRef]

39. Obernberger, I.; Thek, G. Physical characterisation and chemical composition of densified biomass fuels with regard to their combustion behaviour. Biomass Bioenergy 2004, 27, 653-669. [CrossRef]

40. Porcu, A.; Sollai, S.; Marotto, D.; Mureddu, M.; Ferrara, F.; Pettinau, A. Techno-Economic Analysis of a Small-Scale Biomass-to-Energy BFB Gasification-Based System. Energies 2019, 12, 494. [CrossRef]

41. Aktas, T.; Thy, P.; Williams, R.B.; McCaffrey, Z.; Khatami, R.; Jenkins, B.M. Characterization of almond processing residues from the Central Valley of California for thermal conversion. Fuel Process. Technol. 2015, 140, 132-147. [CrossRef]

42. Mureddu, M.; Dessì, F.; Orsini, A.; Ferrara, F.; Pettinau, A. Air- and oxygen-blown characterization of coal and biomass by thermogravimetric analysis. Fuel 2018, 212, 626-637. [CrossRef]

43. Yasin, S.; Behary, N.; Rovero, G.; Kumar, V. Statistical analysis of use-phase energy consumption of textile products. Int. J. Life Cycle Assess. 2016, 21, 1776-1788. [CrossRef]

44. Thunman, H.; Berdugo Vilches, T.; Seemann, M.; Maric, J.; Vela, I.C.; Pissot, S.; Nguyen, H.N.T. Circular use of plastics-transformation of existing petrochemical clusters into thermochemical recycling plants with $100 \%$ plastics recovery. Sustain. Mater. Technol. 2019, 22, e00124. [CrossRef]

45. Jambeck, J.R.; Geyer, R.; Wilcox, C.; Siegler, T.R.; Perryman, M.; Andrady, A.; Narayan, R.; Law, K.L. Plastic waste inputs from land into the ocean. Science 2015, 347, 768-771. [CrossRef]

46. Zhu, P.; Sui, S.; Wang, B.; Sun, K.; Sun, G. A study of pyrolysis and pyrolysis products of flame-retardant cotton fabrics by DSC, TGA, and PY-GC-MS. J. Anal. Appl. Pyrolysis 2004, 71, 645-655. [CrossRef]

47. Ishii, A.; Amagai, K.; Furuhata, T.; Arai, M. Thermal gasification behavior of plastics with flame retardant. Fuel 2007, 86, 2475-2484. [CrossRef]

48. Zhu, J.; Chen, X.; Yao, Z.; Yin, Y.; Lin, K.; Liu, H.; Huang, J.; Ruan, J.; Qiu, R. Directional concentration of bromine from nonmetallic particles of crushed waste printed circuit boards by vacuum-gasification-condensation. J. Clean. Prod. 2019, 231, 462-467. [CrossRef]

49. Nakanishi, S.; Masuko, F.; Hori, K.; Hashimoto, T. Pyrolytic gas generation of cotton cellulose with and without flame retardants at different stages of thermal degradation: Effects of nitrogen, phosphorus, and halogens. Text. Res. J. 2000, 70, 574-583. [CrossRef]

50. Smith, A.D.; Landoll, M.; Falls, M.; Holtzapple, M.T. Chemical production from lignocellulosic biomass: Thermochemical, sugar and carboxylate platforms. In Bioalcohol Production; Elsevier: Amsterdam, The Netherlands, 2010; pp. 391-414. 
51. Jayathilake, R.; Rudra, S. Numerical and experimental investigation of Equivalence Ratio (ER) and feedstock particle size on birchwood gasification. Energies 2017, 10, 1232. [CrossRef]

52. Sarker, S.; Bimbela, F.; Sánchez, J.L.; Nielsen, H.K. Characterization and pilot scale fluidized bed gasification of herbaceous biomass: A case study on alfalfa pellets. Energy Convers. Manag. 2015, 91, 451-458. [CrossRef]

53. Pablos, A.; Aguado, R.; Tellabide, M.; Altzibar, H.; Freire, F.B.; Bilbao, J.; Olazar, M. A new fountain confinement device for fluidizing fine and ultrafine sands in conical spouted beds. Powder Technol. 2018, 328, 38-46. [CrossRef]

54. Vukušić, S.B.; Grgac, S.F.; Katović, D.; Andrea, K. Evolved Gas Analysis and Flame Retardant Characterisation of Textiles treated with Organophosphorus based Compounds. In Proceedings of the World Congress on CBRN Threat and Terrorism, CBMTS-Industry VII, Cavtat, Croatia, 10-15 April 2011.

55. Vecchione, L.; Moneti, M.; Bocci, E.; Carlo, A.D.; Foscolo, P. Steam Gasification of Pine Wood in a Fluidized Bed Reactor: Model Development and Validation at Different Operative Conditions. In Proceedings of the 21st European Biomass Conference and Exhibition, Copenhagen, Denmark, 3-7 June 2013; pp. 841-848.

(C) 2020 by the authors. Licensee MDPI, Basel, Switzerland. This article is an open access article distributed under the terms and conditions of the Creative Commons Attribution (CC BY) license (http://creativecommons.org/licenses/by/4.0/). 